\title{
Evaluation of a Workplace Disability Prevention Intervention in Canada: Examining Differing Perceptions of Stakeholders
}

\author{
Karin Maiwald • Angelique de Rijk • \\ Jaime Guzman • Eva Schonstein • Annalee Yassi
}

Published online: 23 October 2010

(C) The Author(s) 2010. This article is published with open access at Springerlink.com

\begin{abstract}
Introduction Workplace disability prevention is important, but stakeholders can differ in their appreciation of such interventions. We present a responsive evaluation of a workplace disability prevention intervention in a Canadian healthcare organization. Three groups of stakeholders were included: designers of the intervention, deliverers, and workers. The aim was to examine the appreciation of this intervention by analyzing the discrepancies with respect to what these various stakeholders see as the causes of work disability, what the intervention should aim at to address this problem, and to what extent the intervention works in practice. Methods A qualitative research method was used, including data-triangulation: (a) documentary materials; (b) semi-structured interviews with the deliverers and workers
\end{abstract}

Authors' contributions-Karin Maiwald: study design, data gathering and analysis, and writing the manuscript; Angelique de Rijk: analysis and interpretation of data, and significant contribution to manuscript; Jaime Guzman: commenting on design, analysis and manuscript; Eva Schonstein: conception of evaluation study, and commenting on manuscript; Annalee Yassi: commenting on design, analysis and contribution to manuscript.

K. Maiwald $(\square) \cdot$ A. de Rijk

Care and Public Health Research Institute,

Department of Social Medicine,

Faculty of Health, Medicine and Life Sciences,

Maastricht University,

P.O. Box 616, 6200 MD Maastricht,

The Netherlands

e-mail: K.Maiwald@maastrichtuniversity.nl

A. de Rijk

e-mail: Angelique.deRijk@maastrichtuniversity.nl

J. Guzman

Occupational Health \& Safety Agency for Healthcare,

Vancouver, Canada

e-mail: Jaime@ohsah.bc.ca $(\mathrm{n}=14)$; (c) participatory observations of group meetings $(\mathrm{n}=6)$; (d) member-checking meetings $(\mathrm{n}=3)$; (e) focusgroup meetings $(\mathrm{n}=2)$. A grounded theory approach, including some ethnographic methodology, was used for the data-analysis. Results Stakeholders' perceptions of causes for work disability differ, as do preferred strategies for prevention. Designers proposed work-directed measures to change the workplace and work organizations, and individual-directed measures to change workers' behaviour. Deliverers targeted individual-directed measures, however, workers were mostly seeking work-directed measures. To assess how the intervention was working, designers sought a wide range of outcome measures. Deliverers focused on measurable outcomes targeted at reducing work time-loss. Workers perceived that this intervention offered short-term benefits yet fell short in ensuring sustainable return-towork. Conclusion This study provides understanding of where discrepancies between stakeholders' perceptions about interventions come from. Our findings have implications for workplace disability prevention intervention development, implementation and evaluation criteria.

\footnotetext{
J. Guzman

Department of Medicine, Faculty of Medicine,

University of British Columbia, Vancouver, Canada

E. Schonstein

Faculty of Health Sciences, University of Sydney, Sydney,

Australia

e-mail: eva.schonstein@sydney.edu.au

A. Yassi

School of Population and Public Health and Department

of Medicine, Faculty of Medicine, and School of Environmental

Health, College for Interdisciplinary Studies,

University of British Columbia, Vancouver, Canada

e-mail: Annalee.yassi@ubc.ca
} 
Keywords Program evaluation - Workplace - Qualitative research - Disability prevention - Sickness absence . Canada

\section{Introduction}

Work disability is a major problem in western industrialized countries, from the perspective of individual burden, public health, and economic costs. Long-term absence due to disability particularly contributes to these costs [1]. In Canada, as in many other countries, the largest numbers of days lost from work were recorded for full-time employees in health occupations in 2008 [2]. Illness and disability among healthcare workers in British Columbia (BC) costs an estimated one billion dollars annually [3].

Work disability prevention and return-to-work of workers who report sick is a complex phenomenon [4]. In the healthcare sector in $\mathrm{BC}$, a workplace-based initiative called the 'Prevention and Early Active Return-to-work Safely' (PEARS) program was introduced in 2001. To meet the complexity, this intervention was designed by the Occupational Health and Safety Agency for Healthcare (OHSAH) in BC (a governmental agency with bipartite -employer and (labour) union representativegovernance) in collaboration with affiliated researchers, and local employer and union representatives at a regional healthcare organization $[5,6]$. The reason for the bipartite involvement in designing this workplace-based intervention was that earlier studies [5-8] demonstrated the importance of an integrated workplace-based and workfocused approach, which is built around recognizing the importance of getting all the stakeholders involved in effective communication.

The intervention thus was designed to include primary prevention strategies to prevent work disability from occurring, as well as secondary and tertiary prevention strategies to reduce time-loss and to support return-to-work after a sickness absence. The focus of the PEARS program was work-related musculoskeletal disorders. The specific interventions involved individual and work-directed measures, and '20 principles' - a basic framework or set of rules to guide the intervention in practice [9].

Quantitative evaluation of this intervention showed a reduction in work time-loss of registered nurses by $27-40 \%$ (depending on the comparison year), and reduced costs of claims by $27-44 \%[10,11]$. The basic framework of this intervention had been disseminated to other regional healthcare organizations province-wide. The PEARS site of this study had significantly lower average days lost per time-loss claim (30\% reduction) and had significantly lower average compensation costs per time-loss claim than non-PEARS sites (23\% reduction) $[12,13]$.
What is not known from the above evaluations is 'how' this work-place intervention is appreciated by the different stakeholders. In order to attune policy with local workplace needs, stakeholders' perceptions about program workings in workplace reality ought to be considered [13-19].

\section{Aim}

The aim of this article is to examine various stakeholders' appreciation of the intervention by analyzing the discrepancies between what these stakeholders see as the causes of work disability, what the intervention should aim at to address this problem, and to what extent the intervention works in practice.

Further, through collaboration with local stakeholders this inquiry aims to improve and refine program implementation, which may in turn improve its longevity [19-21]. Analysis of discrepancies between relevant stakeholders and unraveling tension between policy and practice can further improve intervention effectiveness [22].

\section{Theoretical Framework}

According to Guba and Lincoln [19], how stakeholders judge the worth of an intervention largely depends on the degree to which this intervention aims to change what they see as the causes of the underlying problem that needs to be addressed. In social constructivist terms, the formulation of a problem is a social construction, reflecting how we make sense of patterns of difference between people [23]. Stakeholders' ideas on possible solutions to address a problem logically follow their ideas about underlying cause(s) [19].

The topic of our evaluation is an intervention for preventing work disability, often referred in the literature as sickness absence. Explanations of sickness absence have traditionally followed a 'reductionist' approach and medical model to treat 'disease or illness'; assuming that lay people, in this case healthcare workers who report sick from work, will respond to 'prescribed' treatments and lifestyle changes [24]. In recent scientific literature, the causes for sickness absence are attributed to (a) the individual worker; and/or (b) workplace/job-station; and/or (c) work organization. In relation to conceptualizing disability prevention, there seems to be a shift away from workers' personal characteristics (physical and psychosocial factors) towards the interaction between the worker and the workplace environment, compensation, and healthcare delivery system in addressing this societal problem [1, 25]. Even though, workplace interventions often focus their strategies on the individual worker's behaviour [26].

Literature suggests that those who design an intervention (planning) often do this with a different rationale or perspective than those who are impacted, that being the 
workers in the workplace [19]. Moreover, program deliverers, this being executers of the planning in the workplace, are charged with translating the policy into daily practice. Designers and deliverers might all have different norms and values than the workers who are most impacted by strategic policy on work disability [20, 21, 27].

In the intervention studied, employer and union representatives were expected to contribute to the design of the intervention, which was intended as the axis for a paradigm shift in the domain of work disability prevention [28]. Traditionally, however, employer and union representatives do not regard each other as 'natural' partners in formulating policies, such as disability prevention interventions. Disability prevention might be regarded as a political arena where differences in perspectives of employer and union representatives exist in relation to perceived power differences.

Several authors argue that to ensure success of interventions, the interventions should reflect the diverse interests of societal stakeholders i.e. those of laypersons, administrators, clinicians and scholarly researchers [14-21, $25,28,29]$. Building collaboration between various stakeholders, however, is often difficult, and action frequently breaks down [30]. This study intends to illuminate where and how stakeholders' differences in perspectives on disability prevention interventions originate and are perpetuated.

\section{Methods}

Qualitative research methods are shown to be useful when exploring stakeholders' perceptions [31]. Data for this study were collected between 2006 and 2008, in one regional health organization in $\mathrm{BC}$ that includes a regional hospital, a community hospital and a community health centre. Data triangulation was used to secure an in-depth understanding of stakeholders' perceptions. This included five types of data collection:

First, administrative and background documents, which included PEARS principles and guides, scientific articles on the intervention and internal evaluation reports on the PEARS program, were reviewed, by first author KM, to develop an understanding of the views and intent of the designers of the program.

Second, we conducted individual semi-structured interviews to ascertain the perspectives of deliverers executing and workers receiving services. Purposive and snowball sampling strategies were used to maximize variability of ideas and obtain information from the full range of stakeholders, including those with negative experiences. Interviews were taped and transcribed verbatim. To be included in this study, participants had to be adults over 18 years old and belong to one of the three above mentioned stakeholder groups.

Program deliverers $(\mathrm{n}=10$; those who were responsible for executing policy on disability prevention, including implementation and evaluation) included: (a) bipartite committee members including employer and union representatives $(\mathrm{n}=3)$, Occupational Health and Safety (OHS) director $(n=1)$ and staff $(n=3$; who performed the initial assessment of workers who reported sick from work, determined program eligibility, and coordinated returnto-work); (b) work-place based physiotherapists $(\mathrm{n}=3$; who provided physiotherapy services and return-to-work planning).

The workers $(\mathrm{n}=4)$ included registered nurse(s), licensed practical nurse(s) and lab technician(s). Types of injuries included work-related musculoskeletal disorders of the back, shoulder(s) and shoulder-neck, based on physicians' medical diagnoses.

Participants in the interviews included 14 women, all between 30 and 60 years of age with a considerable range of working experience in the healthcare sector. All participants took part in the intervention between 2005 and 2008. Individual interviews lasted until saturation of information was reached.

Third, the principal researcher participated in local bipartite committee meetings $(\mathrm{n}=3)$, and annual OHSAHPEARS meetings $(\mathrm{n}=3)$ that included designers and province-wide program deliverers. She made notes of spoken discourse on justifications, explanations, and motives of actions among and between stakeholder groups.

Fourth, notes of spoken discourse within stakeholder groups, i.e. workers only $(n=3)$, were made.

Fifth, notes of spoken discourse during participatory observations of focus group meetings $(\mathrm{n}=2)$ between stakeholder groups were made (See Table 1 for all five types of data collection).

\section{Data Analysis}

The administrative and background documents and the transcribed texts of the interviews were analyzed [19, 32]. The emerging themes were identified and categorized using an open coding system, deriving and developing concepts from the data. Peer review for checking of codes was carried out by researchers outside the setting of this study. Then, a constant comparison of the concepts, to assess the similarities and differences between stakeholders' perceptions, was conducted [33].

Next, separate within stakeholders group discussions were held (member-checking) with the deliverers and the workers to present the preliminary findings, including obtaining feedback on the interpretation of the data to ensure accuracy and increase credibility of the analysis 
Table 1 All five types of data collection

\begin{tabular}{|c|c|c|c|c|}
\hline & \multicolumn{4}{|c|}{ Stakeholders involved in disability prevention at this workplace } \\
\hline & $\begin{array}{l}\text { Those who designed } \\
\text { the intervention }\end{array}$ & $\begin{array}{l}\text { Those who delivered } \\
\text { the intervention }\end{array}$ & & $\begin{array}{l}\text { Those who received } \\
\text { the intervention }\end{array}$ \\
\hline Data collection & $\begin{array}{l}\text { OHSAH } \\
\text { Employer and employee } \\
\text { representatives }\end{array}$ & $\begin{array}{l}\text { Bipartite Committee } \\
\text { OHS director } \\
\text { and program staff } \\
\text { Front-line manager } \\
\text { and union representatives }\end{array}$ & $\begin{array}{c}\text { Work-place based } \\
\text { physiotherapists }\end{array}$ & Workers \\
\hline Documentary materials & $\begin{array}{l}\text { Central PEARS } \\
\text { documents }\end{array}$ & Local PEARS documents & - & \\
\hline $\begin{array}{l}\text { Individual semi-structured } \\
\text { interviews }\end{array}$ & - & $\mathrm{N}=7$ & $\mathrm{~N}=3$ & $\mathrm{~N}=4$ \\
\hline Group meetings & $\mathrm{N}=3$ & $\mathrm{~N}=3$ & & \\
\hline Member-checking & - & $\mathrm{N}=1$ & $\mathrm{~N}=1$ & $\mathrm{~N}=1$ \\
\hline Focus group meetings & - & $\mathrm{N}=2$ & & \\
\hline
\end{tabular}

$[34,35]$. These meetings were used to introduce differing perspectives (on causes, solutions and workings) to each stakeholder group. The meetings were followed by between stakeholder group meetings with the deliverers and workers combined to prioritize issues that needed to be addressed and to find shared solutions to improve the implementation of the local intervention. To facilitate a democratic process for decision-making, the nominal-group technique was used to structure the meetings [36].

Finally, with ethnographic methodology [33, 37] we reconstructed patterns in similarities and differences in stakeholders' perceptions. Here, the stakeholders' perceptions were interpreted in terms of existing theories explaining sickness absence in scientific research; unraveling what sorts of differences in problem definitions regarding sickness absence are visible. Next, emerging patterns regarding perceptions on solutions and the perceived impact of this intervention were re-created. AY, original key designer of the PEARS program, reviewed and discussed interpretation of document analysis to ensure accuracy. Thus, based on assembled evidence, we reconstructed stakeholders' ideas on work disability leading to sickness absence, on possible solutions to address it, and the effectiveness of current program services at this evaluation site in our analysis.

Computer-assisted qualitative data analysis (NVivo) was used to facilitate structuring and coding of data, and to explore relations [32-35, 37].

\section{Ethical Considerations}

Two research ethics boards approved this project. Participants were made aware they were free to refuse to participate. Written consent was obtained before the interviews took place. Participants were requested by the research study team to keep all group discussions confidential, but were aware that the researchers could not guarantee this.

\section{Results}

We present stakeholders' perceptions on what, according to them: (1) are the causes of work disability (their problem definitions); (2) should the solutions be to address these problems; and (3) to what extent this workplace intervention works in practice.

\section{Views on Problem Definitions}

Stakeholder groups defined the causes of work disability in similar ways, however, their emphasis differed. All stakeholders explained work disability as a lack of proper equipment usage, and/or individual behaviour such as skills in using equipment properly. Hereby, deliverers emphasized the attribution of work-related musculoskeletal disorders as a result of 'poor' health of the worker i.e. general fitness and an aging workforce.

/.../ we're aging, I think we've all got aging bodies and we all have probably been lifting things, stuff, for years. (Interview 2)

/.../ start out with older staff, older staff as we age, I don't necessarily think they're necessarily more prone to injury but they may, and this goes for all staff and not, so maybe more physically fit than others and being able to carry out the duties with their position, so certainly physical fitness has something to do with it. (Interview 3)

All stakeholder groups also defined the cause of work disability as a result of physical working conditions, 
improper job-station ergonomics and workplace organization such as work pressures. Hereby, workers emphasized the attribution of work-related musculoskeletal disorders as a result of a high turnover rate of front-line managers and co-workers, which impacted getting the necessary support to deal with work pressures on the floor and having a say in the health organization.

I guess we can go to our manager but I mean, I find that we've had 7 managers in 10 years /.../ and we're rotating through all this new staff all the time, every 2 months or so we rotate through 4 staff, for different rotations right, so your always, like, okay; who am I working with? You don't get to know how they lift, you don't know, do you know what I mean. It's difficult $/ . . . /$ the thing is it's too hard on the floor to have all these new managers and then not being supported. (Interview 8)

Designers and deliverers largely explained that returning to work could be predicted in specific time phases i.e. acute, sub-acute, or chronic phases after reporting sick. Designers and deliverers also both attributed return-towork to workers' skills, to be influenced through individual-directed measures, i.e. education and exercises.

Deliverers moreover attributed return-to-work to workers' motivation, attitude and personality. In this view, return-to-work is to be influenced through individualdirected measures, i.e. persuasion, demonstration, goal setting and re-assurance, to change the worker.

Designers and deliverers agreed that these individualdirected measures were to be supported by work-directed measures, i.e. job station modifications, and workplace organization directed measures, i.e. temporary exemption of duties and hours. One deliverer put it like this:

Two different kinds; the work site assessment basically starts head-to-toe, looking at awkward postures, what force, what equipment is in place, what are the risks, that's pretty much where it starts /.../ And recommendations are made, you know here is plan A, here is plan B, plan C, because lots of times we can't just engineer the problem out, so it might be here is a 'retrofit way' to handle this in the interim, but you may need to consider renovating, because this is an issue and it will be an issue for all of your staff /.../ but the assessments are not just about the physical environment, often times your assessment will take into administrative issues, so, if it was a so called work load. (Interview 11)

In contrast, workers perceived that return-to-work was largely dependent on their physical discomfort-that is the extent to which they can "make it through the day". To support their ability to "make it through the day", work-directed measures were needed, including front-line manager and co-workers support, and a reduction of work pressure on the entire floor. Moreover, according to workers, sustainable return-to-work depended on permanent work-directed measures i.e. 'no-[patient] lift', staffing level and teamwork, thus organizational policy changes.

Views on Possible Solutions

All stakeholders agreed on the importance of a safety work climate in the workplace. This was defined as a work climate that included cooperation and trust between management and unions to address work disability.

As part of this work climate model, the intervention was designed to have a strong primary prevention component, linked to the secondary prevention approach. Designers included primary prevention strategies (prior to reporting sick) including a work-site assessment, to be offered as a continuum by the health organization. Here, recommendations for individual and work-directed measures were to be given by a work-place based occupational health and safety program staff.

Designers emphasized next to a primary prevention focus, a two-pronged approach combining individual and workdirected organization of secondary prevention strategies to support return to work. To achieve this, designers proposed a step-wise approach with detailed ideas about specific steps: early contact with the worker reporting sick from work; a work site assessment, including workplace based occupational health and safety program staff, the front-line manager, the relevant union representative; and the option of workplace-based physiotherapy services. Most steps were to include individual and work-directed measures.

Deliverers agreed with this view in that they executed a two-pronged approach combining individual and workdirected organization of secondary prevention strategies to support return to work.

OHS program staff (part of deliverers) viewed that by making recommendations for work-directed measures for a worker returning to work to the front-line managers, they supported return to work. Deliverers viewed that as the front-line manager implemented work-directed measures for the returning worker, co-workers would also benefit from this measure. Here, deliverers linked their secondary prevention service with the primary prevention component of the intervention.

Workplace-based physiotherapists (part of deliverers) however, focused solutions on individual-directed measures such as (medical) re-assurance, and emphasized to influence the worker's behaviour [read: decision] to return-to-work.

Interviewed workers reasoned that recommendations for work-directed measures coming out of a work site assessment would act as convincing information or evidence for 
the front-line manager to make changes to the workplace/ job station. One worker put it like this:

/.../ needs a new [workplace] room as it is too confined and apparently, there is not enough money in the budget to make any improvements. How else do we know to be able to access a work-site assessment to help with the process of trying to convince the higher up? Or is this program not accessed for that reason? Maybe we are off topic? (Focus group meeting 1)

Workers viewed that that workplace-based physiotherapy services were to ameliorate their physical discomfortin the short term to treat the musculoskeletal injury and offer professional advice-to ensure sustainable return to work in the long term. Workers appreciated receiving this workplace-based service without the involvement of (perceived as particularly unpleasant) insurance personnel, i.e. from WorkSafeBC.

All stakeholders agreed that early graduated return-towork services were to ensure the worker would stay connected and participate at the workplace. Designers and deliverers both agreed return-to-work was also important to reduce costs and increase productivity.

We were paying a lot of these folks' sick leave to stay at home and do nothing when we could be paying them to be at modified work. (Interview 10)

Designers and deliverers differed in the interpretation and meaning of bipartite involvement. Designers and some local bipartite committee members (part of deliverers) were in 'receive-mode' with the aim to obtain feedback and ideas from these stakeholders 'bottom-up' to improve the intervention' workings.

Well, I mean you can send a piece of paper, but that will never get read, you can send an e-mail, they get about a 100 a day, and there's all this nuances. I think and there is no opportunity to ask questions usually so I think a face to face is a way better route to go. I look at a lot more networking than a formal presentation. Letting them know what the possibilities are, allowing questions and answers, you don't get that with the other kinds of things, other stuff. (Interview 10)

However, most bipartite committee members (part of deliverers) were in 'top-down transmit-mode', with the aim to find support for their activities among front-line managers and union representatives during bipartite meetings.

To summarize, stakeholders agreed on possible solutions to support return-to-work, however, differed on their prioritization. It also included differing prioritizing individual and work-directed measures in relation to the returnto-work process, including implementation.
Views on Program (Component) Effectiveness

Designers, OHS bipartite committee members (part of the deliverers) valued monitoring the numbers of workers reporting sick from work. These stakeholders reasoned that as individual-directed and work-directed recommendations fall into place, these numbers will go down. However, deliverers got frustrated when the number of workers reporting sick did not really change over time. Moreover, deliverers started to doubt the value of these 'numbers'. Did perhaps the number of workplace related musculoskeletal disorders go up because the intervention included no charge physiotherapy services? Deliverers viewed that this workplace-based service served as an incentive to report musculoskeletal problems. They also viewed that these numbers didn't tell them 'how' to improve the intervention.

Organizing a work-site assessment that included frontline managers, union representatives and workers together proved difficult in practice. This was mostly due to busy work schedules, vast geographical distances, and a highturnover rate of front-line managers; there was little time to build a working relationship with these important stakeholders. Nor did workers always want all these other stakeholders involved in, according to them, personal business [read: health issues]. Further, workers would have highly appreciated not having to report sick before getting a work-site assessment.

The workplace- based physiotherapists (part of deliverers), perceived that their services mostly targeted the individual worker. If workers returned to work, physiotherapists had reached their goal, that is, to affect workers' behaviour. If workers did not return to work, physiotherapists tended to brush this it off with "you can lead a horse to water, but you cannot get it to drink". These deliverers were not clear on their responsibilities to recommend work-directed measures. They perceived that implementation of recommendation largely depended on front-line managers' willingness to comply. As a consequence, these deliverers were frustrated that their services were only a small part of the returnto-work process.

/.../ we make recommendations; there is a paper trail that those recommendations have been made but depending on the individual manager and how valuable return to work and safety are to them I find sometimes I run into barriers there that people don't get accommodated as well as maybe they should. (Interview 5)

It's challenging because I have no power to change the work site. (Interview 13)

According to workers, work-directed measures, including support by their front-line managers and co-workers, and reduction of organizational work pressures were not in 
line with their individual efforts to return-to-work, which was frustrating:

I didn't see paperwork, they push you out, you come to work, you are out on the floor, you are so busy, everybody sees you, they really want you, so I said 'well I can't do any lifting', I was bullied. They told us we could take micro breaks and stuff but the thing is you know, I mean when you're overworked at the floors and the floor is very heavy and there's limited amount of staff. I had lots of comments say 'well what are you doing here if you can't lift, if you can't work?' (Interview 9)

Workers agreed that return-to-work was effective for staying connected to the work place, it had relevance towards the importance of work in their life, and to their feeling valued for their remaining skills:

You know I enjoy my job, I love my job as a [job position], working with people, to prevent, you know, getting depressed being at home, not able to be out. I mean I've got lots of friends here, my co-workers, we get along well, I mean that's a big one right there, to keep up my skills. (Interview 9)

Bipartite steering committee members (part of deliverers) differed in perceptions on the role and responsibilities of this committee and the meaning of bipartite collaboration to address disability prevention. Designers had used multi-disciplinary evidence-based practices, and various stakeholders' input, to develop, implement and evaluate this workplace intervention. However, local deliverers mostly used their own disciplinary training and experiential knowledge to interpret and implement the intervention.

Additionally, perceptions differed on the process to develop policy on disability prevention. Designers had planned a profound shift in authority-structures: to maintain a power balance between front-line manager and union representatives they had proposed a voting procedure for shared decision-making. In practice, 'voting' never took place. Although front-line manager and union representatives were willing to influence this policy, they were unsure of their roles and responsibilities to achieve this.

I don't even know what my role is as a steering committee member. Am I supposed to be out there connecting with the [people they represent]. I have no clue. /.../ Its like, am I supposed to be doing something here or you know, we, is this just a planning thing, or what is it? (Interview 6)

Difficulties around front-line manager and union representative involvement in the process to develop policy on disability prevention were accentuated when pilot funding by $\mathrm{OHSAH}$ ended and financial costs of maintaining and reviewing this intervention were transferred back to the health organization. Front-line manager and union representatives themselves appeared resigned in the face of a 'traditional top-down' policy-making process: "that is just the way it is around here". (Group meeting 6)

Interviewed workers were not aware this workplace intervention was designed and delivered through front-line manager and union representative involvement. These interviewed workers reported difficulties they encountered in returning to work to their front-line manager, OHS program staff, and workplace based physiotherapists. Union representatives mentioned to reach some members, however, not all and report regional issues to their provincial union.

To summarize, deliverers' views about program effectiveness, including implementation differed from those of designers and workers.

\section{Discussion}

A Canadian work disability prevention intervention named PEARS was evaluated at one site. We examined the perceptions of three stakeholder groups on how they define the causes of work disability, what the intervention should aim at, and to what extent the intervention works in practice. Data was collected from various sources. Based on our data, we concluded that this intervention had been carefully designed with the participation of diverse stakeholders such as the employer and union representatives. A striking similarity among the stakeholder groups was their aspiration to approach work disability as something that can positively be affected by workplace-based interventions. Profound differences in views were, however, found between deliverers and designers, and between deliverers and workers on whether and how workplace-based interventions interact with the worker's disability. Whereas for designers the make-up and dimensions of the problem were mostly tied to the workplace and work organization, the deliverers mostly tied this to the individual worker. For workers, the make-up and dimensions of the problem were mostly tied to the workplace and work organization, including implementation. To workers the work organization did not only relate to addressing work demands when returning to work-in the short term-but moreover, to the quality of work life, including support by front-line managers and co-workers, and organizational policy changes to ensure sustainable return to work-in the long term. Consequently, this differing focus for necessary change across stakeholder groups, and finding temporary versus permanent solutions, may impact the intervention itself and thus work disability.

Local deliverers and workers were frustrated that they were only a small part of the process to improve policy on 
work disability. Power struggles at the provincial and health organization level hampered bipartite steering of this intervention, including implementation. Moreover, it is not clear from this study if local union representatives represent rural healthcare workers at the provincial level.

\section{Differing Conceptions of Cause and Thus Solutions}

Deliverers had a predominant biomedical-psychological and administrative perspective on work disability. They mostly explained the problem in terms of risk factors, causes and phases at the individual level. From this perspective, returnto-work can be strictly planned and prescribed; stepwise early re-integration of workers who report sick from work is what is at stake-the goal is mostly to reduce costs, improve productivity and encourage work participation.

Workers, in contrast, mostly explained work disability in terms of the workplace and work organization. According to them, maintenance of their health is what is at stake, including a 'continuum' perspective to ensure this is achieved, more in line with the designers view. This was consistent with the results of studying the same intervention as implemented in a different health organization [38].

Interviewed workers felt that this intervention did not take measures to ensure sustainable return-to-work, including implementation. Consequently, workers got frustrated; they perceived being blamed for delaying a capricious process that was planned based on time frames outside their control. Even though workers returned to work, they were less motivated to deal with employers' productivity demands.

Ståhl and colleagues [39] also found these profound differences in perspectives on work ability and named these a reductionist view versus a holistic view. However, these were held by different stakeholders than studied here (health professionals and Social Insurance Agency). Guzman and colleagues [40] found that the choice of priorities to address back-pain disability among researchers and occupational health stakeholders is primarily influenced by different views about disability and other components of personal experience.

\section{Program Effectiveness}

Designers and deliverers used formative and administrative criteria to evaluate if program services had been offered i.e. if a work-site assessment had taken place. However, despite the original design's calling for evaluation of whether recommendations for work-directed measures were indeed implemented at the organizational level, this did not take place-although this would have been highly appreciated by designers and the workers.

This is in line with Westmorland and Buys [41], who found that employees expressed concerns about employers who put employees back into work situations where they were at risk of re-injury. These authors reported that there was a lack of follow-up once the worker has returned to work.

Several authors argue that the outcome 'reported injuries' should always be supplemented with measures more inclusive of recurrences of the injuries, and supplemented by other measurements, i.e. impact on work-role functioning and quality of life [42, 43]. Policy-makers and insurance companies are often tempted by guidelines and cost-effectiveness analyses as an ideal way to control work disability prevention interventions, and thus, to control the costs of health care [44].

This study found that stakeholders differed in ideas on the effectiveness of program services.

As a result of the varying dimensions of conceptualizing the underlying problem, and of the differing characteristics on the return-to-work process, their logic on what works to achieve disability prevention differed. OHS director and program staff (part of deliverers) focused on reducing timeloss and cost-benefit analysis-a management and administrative perspective. Workers focused on their health-a health perspective.

Earlier figures showed positive results for PEARS, but focused on reduced time-loss and costs at this health organization. The current study showed that, although intended otherwise by the designers, the intervention seems to have been delivered in a too narrow-scoped way which might reduce workers' motivation and their productivity. Our findings are in line with previous research [45] showing that different groups view success of interventions in significantly different ways.

\section{Bipartite View Versus Unilateral View}

Designers and deliverers also differed in ideas on bipartite collaboration to develop, implement and evaluate this intervention. Roles and responsibilities of these stakeholders were unclear, and agreements on monitoring and reviewing the bipartite process were not endorsed. These differences in perceptions of the meaning of bipartite collaboration/steering to develop policy on disability prevention at this evaluation site, lead to frustration between designers and deliverers. Ideas on bipartite policy formulation, execution, and evaluation of workplace-based interventions might even differ among the designers themselves.

Implementation

Differences between stakeholders seem inevitable and even indispensable. An earlier study [46] found that lay persons as well as professionals involved in health care decisionmaking recognized the importance of incorporating a 
diversity of expertise and opinion. This could be addressed by, among other things, paying attention to processes by which decisions are reached. As a result, participants will explore a wider range of possible solutions and reach decisions in the interest of everyone.

This study found that RTW coordinators and workplacebased physiotherapists (both deliverers) complained that they did not oversee the complexity of work disability. They were unsure about, and some were overwhelmed with, responsibilities for measures to be executed within this local intervention. Additionally, they had few means to actually implement workplace and/or work organization change besides forwarding information, i.e. paper trails, 'preaching', facilitate discussions between the worker and the workers' front-line manager. These difficulties can be regarded as the difficulty of interdisciplinary teams. Durand and colleagues [47] attributed implementation difficulties to the diversity of interventions and proposed to have agreements in place that are more precise in regard to the content of measures. Pransky and colleagues [48] attributed such difficulties to a lack of specific attributes by RTW coordinators and argued for specific training.

A second problem shown in this study was the limited focus on intervention at the individual level. Although both individual and work-directed measures were designed, most deliverers tended to individualize the focus of change. This was based on their disciplinary background; practical experiences (overseeing complexity, overwhelmed with responsibilities, means-or lack thereof) and finally, the underlying norms and beliefs that the problem to address is mostly behaviour related. Designers had proposed a continuum, an on-going, non-linear process, of seeking best solutions to address disability prevention through bipartite 'top and bottom' dialogue that included multidisciplinary collaboration with employer and union representatives. Stakeholders will always differ but can only compromise on solutions. However, this shift in authority requires time and money, and when pilot funding to this regional health organization stopped, this process stopped.

Finally, we found that in a multi-pluralistic health organization stakeholders may respond to policy differently. When the policy on bipartite collaboration/steering and policy on individual and organizational change fits local traditions-they may be easily internalized by the individuals and by the organization, whereas if they differ they may not [27]. The execution of policy is thus a rather capricious process in reality, which needs continuous attuning with (local) workplace reality [49].

\section{Methodology Discussion}

The findings of this study are limited to the local context. However, as our discussion shows, the findings match with the literature and have broader implications for workplace interventions. The small number of interviewees could be seen as a limitation. The study was designed to conduct interviews and focus groups with all three stakeholder groups. However, formal interviews, and focus groups were only conducted with the deliverers and workers. By recruiting participants through purposive and snowball sampling strategies, we addressed not getting a selection of dissatisfied interviewees only. Although it is not unusual in responsive evaluation to compare the perspectives of program deliverers and receivers with that in written policies [19], interview material would have added more depth. The use of data-triangulation improves the validity of the findings presented here, including observations of meetings in which designers participated, and verification with designer, coauthor AY.

The selection procedure of including three different stakeholder groups, and our dialectic and pluralistic approach support this study in getting an in-depth insight and understanding of workplace-based practical reality of workplace interventions.

\section{Conclusion}

Recognizing differing perspectives alone is not sufficient in the arena of work disability. In our view, improving our understanding of the background of stakeholders' logic and reasoning is a next step towards a more productive working relation and relationship between relevant stakeholder groups.

This study identified that deliverers' reasoning on the prevention of work disability and leading to sickness absence are not in agreement with the reasoning of workers. For deliverers, the focus is on productivity, encourage work participation and indeed saving money, which can be managed by a clear stepwise approach. For workers, their health is indeed at stake whereby prevention and sustainable return to work is a continuum process, including implementation. More specific, this includes implementation of workplace and work organization changes, which includes modifying work demands and improve social support-in the long term. In brief, what is at stake for workers to address work disability is organizational policy change. The latter is more in line with designers' intentions.

The existing discrepancies in perspectives of the stakeholders correspond to the natural differences. Even though the current study sheds new light on this, it also showed that these differences do not prevent many similarities to exist among the stakeholders on workplace-based intervention components to approach work disability. In the end, stakeholders can only compromise on common interventions for different reasons. Our findings show the 
consequences of these differences and compromises in regard to workplace disability prevention intervention development and implementation. This study also provides ideas to guide the design of evaluation research on work disability. We recommend including various measures for success at various levels and at varying time-lines, representing the differing stakeholder perspectives.

Furthermore, professional education and training on improving workplace-based intervention structures and procedures differs among the deliverers. These issues complicate agreement on appropriate strategies to address work disability at this health organization, including implementation.

Calls for employer and union representatives to cooperate in an approach to work disability and interventions at the workplace have an undeniable logic. However, the present study in the Canadian context suggests that constitution of a bipartite committee is not a full guarantee for a productive analysis of this public health problem, nor for workplace-based interventions, including implementation in practice.

Acknowledgments We are grateful to the participants of this study and Philip Mah, OHSAH and Karen Lockhart, University of British Columbia (UBC) for their kind assistance. Sources of financial support in the form of a research fellowship and project funding came from the Occupational Health \& Safety Agency for Healthcare (OHSAH), BC and a health organization, BC, Canada. Funding does not imply endorsement of the research findings. Annalee Yassi acknowledges the funding of the Canada Research Council to support her work in this project. Ilse Mesters, PhD, Department of Health Education \& Health Promotion, Prof. R. A. de Bie, PhD, Department of Epidemiology, and Anja Krumeich, PhD, Department of Health Ethics and Society, Care And Public Health Research Institute (CAPHRI), Maastricht University, Netherlands supported this study.

Conflict of Interest The authors declare that no competing interests or conflicting interests exist.

Open Access This article is distributed under the terms of the Creative Commons Attribution Noncommercial License which permits any noncommercial use, distribution, and reproduction in any medium, provided the original author(s) and source are credited.

\section{References}

1. van Oostrom SH, Driessen MT, de Vet HCW, Franche RL, Schonstein E, Loisel P, van Mechelen W, Anema JR. Workplace interventions of preventing work disability. Cochrane Database of Systematic Reviews. 2009, Issue 2.

2. Stats Canada, 2008. Available from: http://www.statcan.gc.ca/ pub/71-211-x/2009000/part-partie1-eng.htm.

3. Auditor General of British Columbia. 2004/2005 Report 2: In Sickness and in Health. Available from: http://www.llbc.leg.bc. ca/public/PubDocs/bcdocs/370018/Report2_in-sickness-and-health. pdf.

4. Loisel P, Buchbinder R, Hazard R, Keller R, Scheel I, van Tulder $\mathrm{M}$, et al. Prevention of work disability due to musculoskeletal disorders: the challenge of implementing evidence. J Occup Rehabil. 2005;15(4):507-24.

5. Yassi A, Curtis J, Miles-Tapping C, Vallentyne S. Prevention, early intervention and return to modified work program to decrease the incidence and severity of back injuries in nurses: the launching of a pilot program. Can J of Rehabil. 1991;4(3A):25-6.

6. Cooper J, Tate R, Yassi A. Work hardening in an early return to work program for nurses with back injury. Work. 1997;8:149-56.

7. Friesen M, Yassi A, Cooper J. Return-to-work: the importance of human interactions and organizational structures. Work. 2001; 17:11-22.

8. Yassi A, Ostry A, Spiegel JM. Injury prevention and return to work: breaking down the two solitudes. In: Sullivan T, Frank JW, editors. New views on preventing work-related disability. Taylor \& Francis Books Ltd.; 2003. p. 75-86.

9. Yassi A, Ostry AS, Hatter B, De Boer HM. Joint health and safety committee education and the value of bipartite cooperation in the healthcare sector in British Columbia, Canada. Int J Occup Environ Health. 2005;11:305-12.

10. Davis PM, Badii M, Yassi A. Preventing disability from occupational musculoskeletal injuries in an urban, acute and tertiary care hospital: results from a prevention and early active return-towork safely program. J Occup Environ Med. 2004;46(12): 1253-62.

11. Badii M, Keen D, Yu S, Yassi A. Evaluation of a comprehensive integrated workplace-based program to reduce occupational musculoskeletal injury and its associate morbidity in a large hospital. J Occup Environ Med. 2006;48(11):1159-65.

12. OHSAH-materials. In-house formal and informal documents on the PEARS program i.e. cost effectiveness of the PEARS program, Jan 12, 2006.

13. OHSAH-website. Available from: http://www.ohsah.bc.ca.

14. MacEachen E, Clarke J, Franche RL, Irvin E. Systematic review of the qualitative literature on return to work after injury. Scand $\mathbf{J}$ Work Environ Health. 2006;32(4):257-69.

15. Frank J, Sinclear S. Preventing disability from work-related lowback pain. New evidence fives new hope-if we can get all the players onside. Can Med Assoc J. 1998;158(12):1625-31.

16. Guzman J, Yassi A, Baril R, Loisel P. Decreasing occupational injury and disability: the convergence of systems theory, knowledge transfer and action research. Work. 2008;30(3): 229-39.

17. Eakin J, MacEachen E. Health and the social relations of work: a study of the health-related experiences of employees in small workplaces. Sociol Health Illn. 1998;20:896-914.

18. Franche RL, Baril R, Shaw WS, Nicholas M, Loisel P. Workplace-based return-to-work Interventions: optimizing the role of stakeholders in implementing and research. J Occup Rehabil. 2005;15(4):525-42.

19. Guba EG, Lincoln YS. Fourth generation evaluation. 1st ed. Thousand Oaks, CA: Sage Publications; 1989.

20. Linnan LA, Sorensen G, Colditz G, Klar N, Emmons KM. Using theory to understand the multiple determinants of low participation on worksite health promotion programs. Health Educ Behav. 2001;28(5):591-607.

21. Patton MQ. Utilization-focused evaluation: the new century text. 3rd ed. Thousand Oaks, CA: Sage Publications; 1997.

22. Meershoek A, Horstman K, Plass S, Vos R. Wat regelen regels? (What do rules arrange?) In: Abma $\mathrm{T}$, in't Veld $\mathrm{R}$, editors. Handboek beleidswetenschap (Handbook of policy science). Amsterdam: Boom; 2001. p. 236-248.

23. Clarke J, Cochrane A. The social construction of social problems. In: Saraga E, editor. Embodying the social: constructions of difference. London: Routledge; 1998.

24. Murray SA, Manktelow K, Clifford C. The interplay between social and cultural context and perceptions of cardiovascular disease. J Adv Nurs. 2000;32(5):1224-33. 
25. Loisel P, Durand M, Berthelette D, Vézina N, Baril R, Gagnon D, et al. Disability prevention: new paradigm for the management of occupational back pain. Dis Manag Health Outcomes. 2001;9(7): 351-60.

26. Cox T, Stavroula L, Ivanov I, Kortums E. Work, employment and mental health in Europe. Work Stress. 2004;18(2):179-85.

27. Stone DA. Policy paradox: the art of political decision making (Revised Edition ed.). New York, London: W.W. Norton \& Company; 2002.

28. Yassi A. Health promotion in the workplace - the merging of paradigms. Meth Inf Med. 2005;44:278-84.

29. Baril R, Clarke J, Friesen MN, Stock S, Cole D, Work-Ready Group. Management of return-to-work programs for workers with musculoskeletal disorders: a qualitative study in three Canadian provinces. Soc Sci Med. 2003;57:2101-14.

30. de Rijk A, van Raak A, van der Made J. A new theoretical model for cooperation in public health settings: the RDIC model. Qual Health Res. 2007;17(8):1103-16.

31. Schwandt TA. Three epistemological stances for qualitative inquiry: interpretivism, hermeneutics, and social constructivism. 2nd ed. Thousand Oaks, CA: Sage Publications; 2000.

32. Corbin J, Strauss A. Basics of qualitative research: techniques and procedures for developing grounded theory. 3rd ed. Thousand Oaks, CA: Sage publications; 2008.

33. Hammersley M, Atkinson P. Ethnography: principles in practice. London: Routledge; 1995.

34. Denzin NK, Lincoln YS. Handbook of qualitative research. Thousand Oaks, CA: Sage Publications; 2000.

35. Polit DF, Beck CT. Nursing research: principles and methods. 7th ed. Philadelphia, PA: Lippincott Williams \& Wilkins; 2004.

36. Delbecq A, Van de Ven A, Gustafson D. Group techniques for program planning: a guide to nominal group and delphi processes. IL: Glenview; 1975.

37. Tedlock B. Ethnography and ethnographic representation. In: Denzin NK, Lincoln YS, editors. Handbook of qualitative research. 2nd ed. Thousand Oaks, CA: Sage Publications; 2000. p. $455-86$.

38. Ouellette V, Badii M, Lockhart K, Yassi A. Worker satisfaction with a workplace injury prevention and return-to-work program in a large Canadian hospital: the importance of an integrated approach. Work. 2007;10(1):44-52.

39. Ståhl C, Svensson T, Petersson G, Ekberg K. The work ability divide: holistic and reductionist approaches in Swedish interdisciplinary rehabilitation teams. J Occup Rehabil. 2009;19(3): 264-73.

40. Guzman J, Jones D, Cassidy JD, Furlan AD, Loisel P, Frank JW. Key factors in back disability prevention: what influences their relative prioritization? Spine. 2007;32(9):E281-9.

41. Westmorland MG, Buys N. A comparison of disability management in Australian and Canadian workplaces. Work. 2004;23: $31-41$.

42. Krause N, Frank JW, Dasinger LK, Sullivan TJ, Sinclear SJ. Determinants of duration of disability and return-to-work after work-related injury and illness: challenges for future research. Am J Ind Med. 2001;40:464-84.

43. Lorig K, Stewart A, Ritter P, Gonzalez V, Laurent D, Lynch J. Outcome measures for health education and other health care interventions. 1st ed. Thousand Oaks, CA: Sage Publications; 1996.

44. LeDou J. Occupational medicine: the case for reform. Am J Prev Med. 2005;28(4):396-402.

45. Melles T, McIntosh G, Hall H. Provinder, payor, and patient outcome expectations. J Occup Rehabil. 1995;5(2):57-69.

46. McKie J, Schrimpton B, Hurworth R, Bell C, Richardson J. Who should be involved in health-case decision making? A qualitative study. Health Care Anal. 2008;16(2):114-26.

47. Durand MJ, Vézina N, Loisel P, Baril R, Richard MC, Diallo B. Workplace interventions for workers with musculoskeletal disabilities: a descriptive review of content. J Occup Rehabil. 2007; 17(1):123-36.

48. Pransky G, Shaw WS, Loisel P, Hong QN, Désorcy B. Development and validation of competenties for return to work coordinators. J Occup Rehabil. 2010;20(1):41-8.

49. Meershoek A, Krumeich A, Vos R. Judging without criteria? Sickness certification in Dutch disability schemes. Sociol Health Illn. 2009;29(4):497-514. 